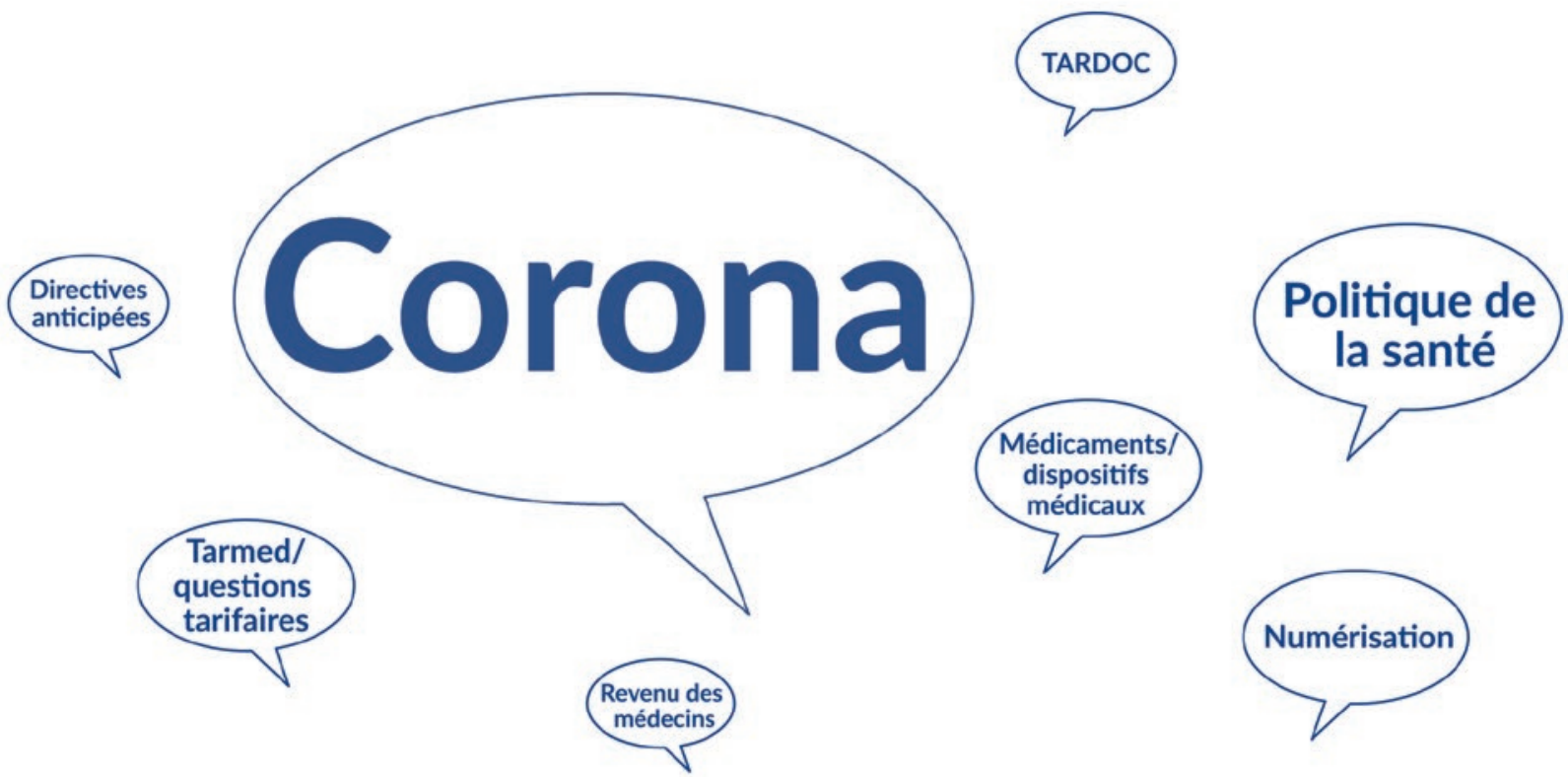

\title{
2020 ne se résume pas au COVID-19
}

\section{Ursina Pally Hofmann}

Dre iur., Secrétaire générale de la FMH

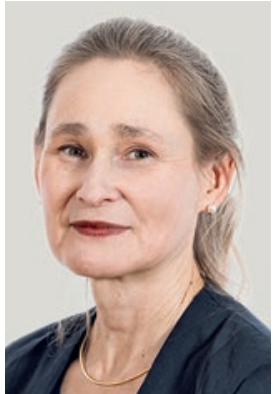

En 2020, un seul et unique sujet a éclipsé non seulement les rapports annuels mais aussi un grand nombre d'autres thèmes bien plus intéressants. Il vaut néanmoins la peine de s'attarder un peu sur les autres événements de l'année écoulée et de ne pas se focaliser uniquement sur la pandémie. Après avoir fait peau neuve l'année dernière, notre rapport annuel désormais plus interactif remplit sa mission et vous présente, au moyen de chiffres, de textes et de graphiques, toutes les activités que nous avons menées durant cette année extraordinaire.

En plus des nombreuses prestations qui jalonnent notre activité quotidienne, comme le soutien aux membres, la mise à disposition d'informations ou encore l'organisation et le suivi de réunions, nous avons aussi publié la statistique médicale, réalisé une enquête sur l'acceptation des offres numériques dans le cadre du suivi des patients et remis le TARDOC au Conseil fédéral pour qu'il l'approuve. Mais ce n'est pas tout. Durant l'année écoulée, nous avons mis sur pied une formation à destination des expert-e-s en responsabilité civile médicale avec la société Swiss Insurance Medicine (SIM) et édité la version remaniée du guide «Bases juridiques pour le quotidien du médecin». Nous avons fondé la communauté DEP AD Swiss avec HIN et la Caisse des médecins, permettant ainsi au corps médical suisse de devenir lui-même un fournisseur d'accès au dossier électronique du patient. Sur le front de la pandémie, nous avons dès le début publié différents documents sur notre site internet, dont une FAQ qui est régulièrement mise à jour et un plan de protection pour les cabinets médicaux. Enfin, la FMH s'est investie pour vous dans divers dossiers politiques et a, pour la première fois de son histoire, accueilli une femme à sa tête en la personne d'Yvonne Gilli.

Vous en apprendrez davantage dans notre nouveau rapport annuel qui vient d'être publié à l'adresse https://report2020.fmh.ch/fr/index.cfm

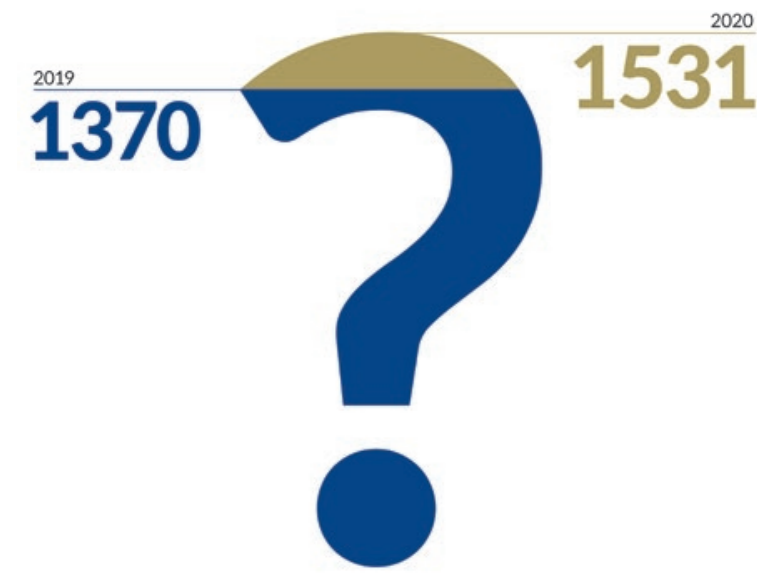

Nombre de renseignements juridiques donnés 